\title{
Involvement of Bax Redistribution in the Induction of Germ Cell Apoptosis in Neonatal Mouse Testes
}

\author{
Elia Damavandi ${ }^{1}$, Yoshitaka Hishikawa ${ }^{1}$, Shin-ichi Izumi ${ }^{1}$, Masashi Shin ${ }^{1}$ and \\ Takehiko Koji ${ }^{1}$
}

${ }^{1}$ Department of Histology and Cell Biology, Nagasaki University School of Medicine, Nagasaki 852-8523

Received November 14, 2002; accepted December 12, 2002

Germ cell death is very common in mammalian testis, during both early testicular development and in the adult period, however the molecular mechanisms underlying the induction of germ cell apoptosis in mouse testes are largely unknown. The aim of this study was to investigate the possible involvement of Bcl-2 and Bax in induction of germ cell apoptosis in immature and mature mouse testes. To gain insights into downstream molecular cascades, we examined the expression of cytochrome $c$ and activated caspase-3. Testes of adult and neonatal mice at $0,6,12$ and 18 days after birth were used. Germ cell apoptosis was evaluated by Terminal dUTP nick end-labeling (TUNEL) staining and the expression of apoptosis-related proteins was examined by enzyme-immunohistochemistry. TUNEL-positive germ cells appeared at 6 days after birth, reaching a maximum number at 12 days after birth, when such cells were identified as gonocytes or spermatogonia. In contrast, by 18 days, the main popula- tion of TUNEL-positive cells comprised spermatocytes and the average number of positive cells per seminiferous tubule remained nearly constant thereafter. The expression of $\mathrm{Bcl}-2$ and $\mathrm{Bax}$ remained constant in germ cells from 0 to 12 days after birth. However, during that period we observed a dramatic redistribution of Bax staining from the cytoplasm to the whole cell including the nucleus. In parallel with the Bax redistribution, cytochrome c staining spread to the cytoplasm and activation of caspase-3 occurred. Moreover, in mirror sections of neonatal and adult testes, we confirmed a strong correlation among TUNEL-staining and Bax redistribution accompanying the cytochrome $c$ redistribution and activation of caspase-3. The temporal and spatial association of Bax and spatial apoptosis-related protein expression with TUNEL-positive germ cells indicates that Bax redistribution may be a trigger for the induction of germ cell apoptosis in mouse testes.

Key words: Apoptosis, Bax/Bcl-2, Spermatogenesis, Cytochrome c, Caspase-3

\section{Introduction}

Apoptosis is essential for the removal of unnecessary or over-produced cells during various developmental processes, including mammalian spermatogenesis [32, 39]. Indeed, during mature mammalian spermatogenesis, 25$75 \%$ of the expected sperm count is lost naturally $[12,13$, 27]. In addition, during fetal and neonatal stages of rodent

Correspondence to: Takehiko Koji, PhD, Department of Histology and Cell Biology, Nagasaki University School of Medicine, 1-12-4 Sakamoto, Nagasaki 852-8523, Japan. testis development, significant numbers of primordial germ cells and spermatogonia disappear $[31,40]$.

Apoptosis, which can be distinguished from necrosis, is an active mode of cell death, originally characterized electron-microscopically by Kerr [14]. Electron microscopic features of apoptotic germ cells are quite unique; the process consists of three discrete stages, early, intermediate and late, and in the final stage the morphology mostly resembles necrosis. The terminal dUTP nick end-labeling (TUNEL) is very useful to identify apoptotic germ cells, since internucleosomal DNA double-strand breaks are accompanied by morphological changes of apoptosis [16, 30]. Using these 
methods, we previously confirmed the frequent occurrence of germ cell apoptosis in mice at around 10-13 days after birth [40]. In mice, during the first 5 days after birth, mitotically arrested gonocytes within the testicular cords re-enter the cell cycle, differentiate into spermatogonia and start to proliferate actively. At approximately day 10, spermatogonia start to differentiate into spermatocytes, and undergo meiosis [24]. By day 35 [25] spermatozoa appear in the lumen of seminiferous tubules and a subsequent wave of spermatogenesis occurs continuously. Therefore, the abundancy of spermatogonial cell death in the first wave of spermatogenesis seems to be a critical factor to determine the number of germ cells produced by the following spermatogenesis. However, our understanding of the molecular mechanism underlying the induction of the neonatal germ cell apoptosis is largely limited. Proteins of the Bcl-2 family are regarded as key regulators of apoptosis [1, 43]; certain members promote cell survival (Bcl-2, Bcl-xl and Bcl-w) while others promote cell death (Bax, Bad, Bak and Bim). The ratio of these molecules has been implicated as a critical determinant of cell fate, where an elevated level of Bcl-2 favors extended survival of cells and an increasing level of Bax expression accelerates cell death [2, 29, 37]. In fact, studies using knockout mice also suggest that members of the Bcl-2 family play an important role in the spermatogenesis [15]. Adult mice lacking the pro-apoptotic protein Bax displayed accumulation of pre-meiotic germ cells and accelerated apoptosis of mature germ cells leading to complete cessation of sperm production. Moreover, significant inhibition of germ cell apoptosis in the neonatal mouse testis was observed in the Bax knockout mice. Although different molecular pathways can be triggered to induce germ cell apoptosis depending upon the situation [16], these accumulated data suggest an essential role for Bax in the regulation of germ cell apoptosis in the first wave of spermatogenesis. However, our knowledge of the balance of Bax and Bcl-2 expression and its direct association with germ cell apoptosis in individual cells remains limited. Furthermore, it would be interesting to address whether changes in that balance accompany the release of cytochrome $\mathrm{c}$ and the subsequent activation of caspase- 3 .

In the present study, we investigated the extent of apoptosis in neonatal mouse testes by TUNEL staining and correlated the proportion of TUNEL-positive cells with the expression of Bax and Bcl-2 on an individual cell basis using mirror sections. In addition, we investigated the localization of cytochrome $\mathrm{c}$ and activated caspase- 3 immunohistochemically as down-stream components of apoptosis-inducing signal transduction.

\section{Materials and Methods}

\section{Chemicals and biochemicals}

Paraformaldehyde (PFA) was purchased from Merck (Darmstadt, Germany) and 3,3'-diaminobenzidine-4HCl (DAB), bovine serum albumin (BSA) and proteinase $\mathrm{K}$ were purchased from Wako Pure Chemicals (Osaka, Japan). Brij
35 was from Sigma Chemical Co. (St. Louis, MO). Biotin16-dUTP and terminal deoxynucleotidyl transferase (TdT) were from Roche Diagnostics (Mannheim, Germany). Other reagents used in this study were from Wako Pure Chemicals or Sigma.

\section{Antibodies}

Rabbit polyclonal anti-Bcl-2 (N-19), rabbit polyclonal anti-Bax (P-19) and rabbit polyclonal anti-cytochrome c (H104) were purchased from Santa Cruz Biotechnology Inc. (Santa Cruz, CA). Anti-human/mouse caspase-3 active was from Techne Corporation (MN). Horseradish peroxidase (HRP)-conjugated goat anti-rabbit IgG $\mathrm{F}(\mathrm{ab})_{2}$ ' was purchased from MBL (Nagoya, Japan). HRP-conjugated goat anti-biotin was from Vector Laboratories (Burlingame, CA).

\section{Tissue preparation}

Male ICR mice at $0,6,12$ and 18 days and 7 weeks after birth were used in the present study. The testes were divided into two groups. In the first group, tissue samples were fixed in 4\% PFA in $10 \mathrm{mM}$ PBS (pH 7.2) overnight and embedded in paraffin using standard procedures. The sections were later stained with hematoxylin and eosin and used for histological evaluation of normal tissue. The second group was fixed with $2.5 \%$ glutaraldehyde in $0.1 \mathrm{M}$ sodium phosphate buffer (SPB), $\mathrm{pH} 7.4$, and then processed routinely and embedded in Epon 812 (Taab Lab., Aldermastton, Berkshire, UK). The experimental protocol was approved by the Ethics Review Committee for Animal Experimentation of Nagasaki University School of Medicine.

\section{Electron microscopy}

Epon-embedded testes were cut into semithin and ultrathin sections. The semithin sections were stained with toluidine blue, and the ultrathin sections were stained with uranium acetate and lead nitrate. The ultrathin sections were observed under a JEOL 1200 EX electron microscope at accelerated voltage of $60 \mathrm{kV}$ as described previously [9].

\section{TUNEL staining}

To identify nuclei with DNA strand breaks at the cellular level, TUNEL was performed according to the method of Gavrieli [6]. Paraffin sections (4-5 $\mu \mathrm{m}$ thick) were cut onto silane-coated glass slides, dewaxed with toluene, and rehydrated in a graded ethanol series. After washing with PBS, sections were treated with $1 \mu \mathrm{g} / \mathrm{ml}$ of proteinase $\mathrm{K}$ in $\mathrm{PBS}$ at $37^{\circ} \mathrm{C}$ for $15 \mathrm{~min}$. The sections were then rinsed once with deionized distilled water and incubated with TdT buffer [25 mM Tris/HCl buffer ( $\mathrm{pH}$ 6.6), containing $0.2 \mathrm{M}$ potassium cacodylate and $0.25 \mathrm{mg} / \mathrm{ml} \mathrm{BSA]}$ alone at room temperature for $30 \mathrm{~min}$. After incubation, the slides were reacted with $100 \mathrm{U} / \mathrm{ml}$ TdT dissolved in TdT buffer supplemented with $5 \mu \mathrm{M}$ biotin-16-dUTP, $20 \mu \mathrm{M}$ dATP, $1.5 \mathrm{mM} \mathrm{CoCl}_{2}$, and $0.1 \mathrm{mM}$ dithiothreitol at $37^{\circ} \mathrm{C}$ for $90 \mathrm{~min}$. The reaction was terminated by washing with $50 \mathrm{mM}$ Tris/HCl buffer $(\mathrm{pH}$ 7.5) for $15 \mathrm{~min}$. Endogenous peroxidase activity was inhibited by immersing the slides in $0.3 \% \mathrm{H}_{2} \mathrm{O}_{2}$ in methanol 
at room temperature for $15 \mathrm{~min}$. The signals were detected immunohistochemically with HRP-conjugated goat antibiotin antibody as described previously $[8,38]$.

For statistical analysis, TUNEL-positive cells were counted as apoptotic cells by examining 200-1000 germ cells in each case, and the frequency was finally expressed as the number of apoptotic germ cells per 500 germ cells (mean \pm SEM). Data for different groups were compared for statistical difference using Student's $t$-test. A $P$ value of $<0.05$ denoted the presence of a significant difference.

\section{Immunohistochemistry}

Immunohistochemical staining for Bax, Bcl-2, cytochrome $\mathrm{c}$ and activated caspase- 3 was performed at room temperature as described previously [2]. Briefly, paraffin- embedded sections were deparaffinized and washed with PBS for $5 \mathrm{~min}$. For the detection of Bax, the slides were autoclaved in $10 \mathrm{mM}$ citrate buffer $(\mathrm{pH} 6.0)$ for $10 \mathrm{~min}$ at $121^{\circ} \mathrm{C}[3]$. After inactivation of endogenous peroxidase activity, as described above, the sections were incubated for 1 hr with PBS containing $500 \mu \mathrm{g} / \mathrm{ml}$ normal goat $\mathrm{IgG}$ and $1 \%$ BSA. The sections were then reacted with rabbit polyclonal anti-Bax (P-19, 1:400), rabbit polyclonal anti-Bcl-2 (N-19, 1:100), rabbit polyclonal anti-cytochrome c $(\mathrm{H}-104,1: 40)$, and rabbit polyclonal anti-human/mouse activated caspase-3 (1:50) overnight. After washing with $0.075 \%$ Brij 35 in PBS, the sections were incubated with HRP-goat anti-rabbit IgG $\mathrm{F}(\mathrm{ab})_{2}{ }_{2}(1: 200)$ for $1 \mathrm{hr}$. After appropriate washing, the sites of HRP were visualized as described above. As a negative control, some sections were reacted with normal rabbit $\mathrm{IgG}$
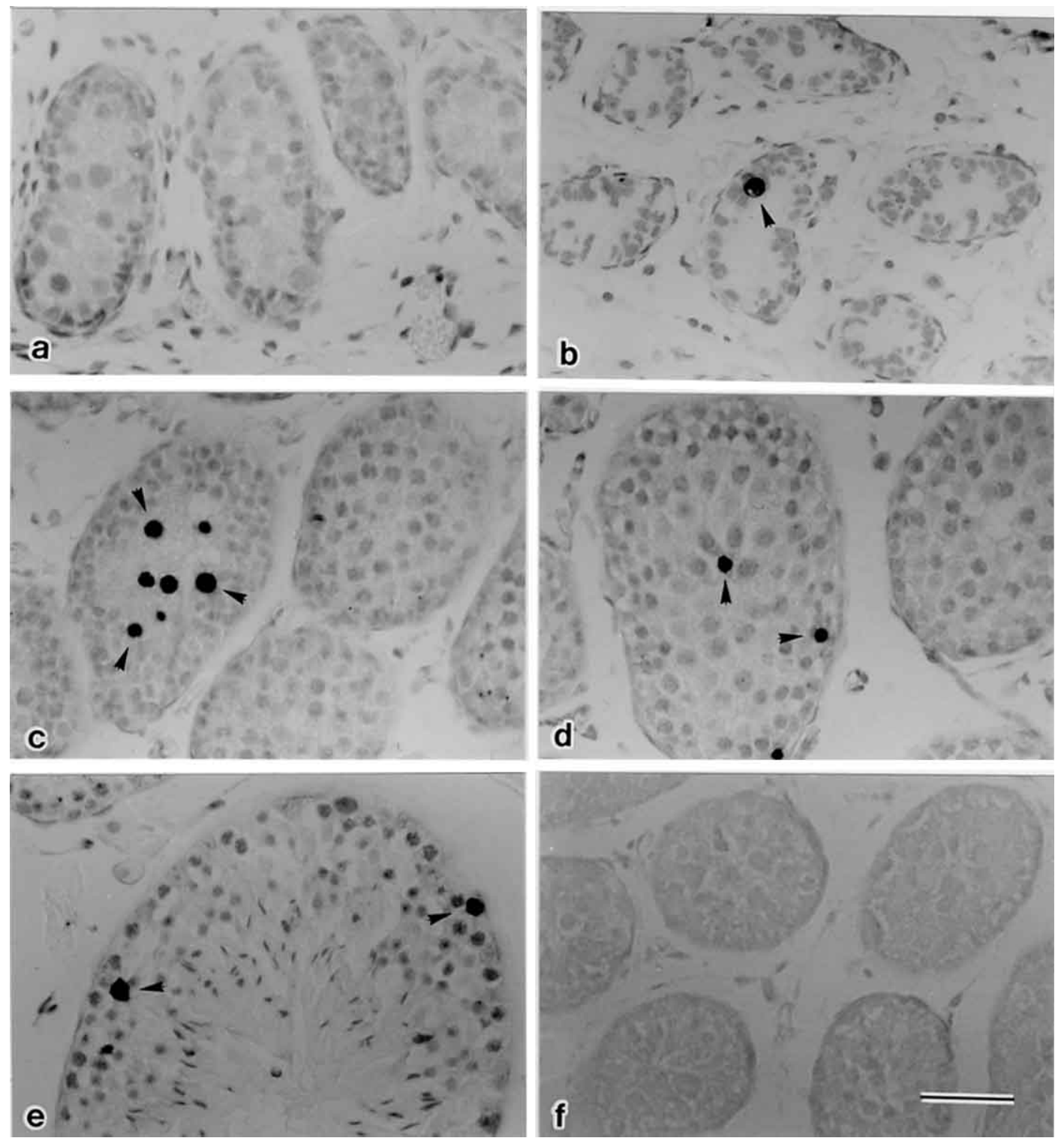

Fig. 1. TUNEL staining of apoptotic germ cells in developing mouse testes. (a) TUNEL staining at the time of birth, (b) 6 days after birth, (c) 12 days after birth, (d) 18 days after birth, and (e) adult at 7 weeks after birth. Arrowheads indicate positive cells. (f) TUNEL reaction was conducted omitting TdT as a negative control at 12 days after birth. All micrographs were taken at the same magnification. Bar=50 $\mu \mathrm{m}$. 


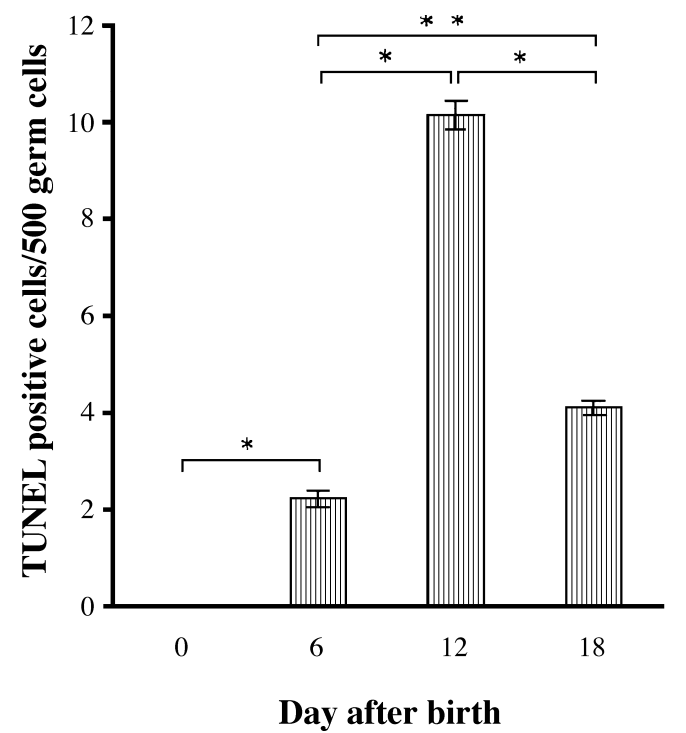

Fig. 2. Quantitative analysis of TUNEL-positive cells in neonatal mouse testes. TUNEL-positive germ cells were counted as the number per 500 germ cells (mean \pm SEM) from 3 mice at the indicated time during neonatal development. $*(\mathrm{p}<0.01)$ and $* *(\mathrm{p}<0.05)$ representing significant differences.

instead of the specific antibodies. These antibodies did not cross-react with each other. As positive controls for Bax and Bcl-2, we used paraffin-embedded sections of mouse intestine as described previously [19]. Mouse liver and ovary were used as positive controls for cytochrome $\mathrm{c}$ and activated caspase-3 immunostaining, respectively [4, 45]. To correlate the expression of these apoptosis-related antigens with TUNEL-positive cells at the level of individual cells, we prepared serial or mirror sections.

\section{Results}

\section{Analysis of germ cell apoptosis by TUNEL staining}

To assess the presence of germ cell apoptosis in the first wave of spermatogenesis, we conducted TUNEL staining on paraffin-embedded sections of mouse testes. As shown in Figure 1, there were no TUNEL-positive cells present at birth, whereas a few positive germ cells appeared at 6 days after birth. Thereafter, TUNEL-positive germ cells increased in number and were most abundant at 12 days after birth, identifiable as gonocytes or spermatogonia and located in the center part of seminiferous tubules (Fig. 1c). The number of TUNEL-positive germ cells, however, decreased in 18-day-old and adult testes (Fig. 1d, e). At 18 days, the main population of TUNEL-positive germ cells comprised spermatocytes and the average number of positive cells per seminiferous tubule remained nearly constant thereafter. Sections that were subjected to the reaction without TdT as a negative control yielded no TUNEL staining (Fig. 1f).

Quantitative analysis of the number of TUNEL-positive cells as shown in Figure 2, revealed that the number of

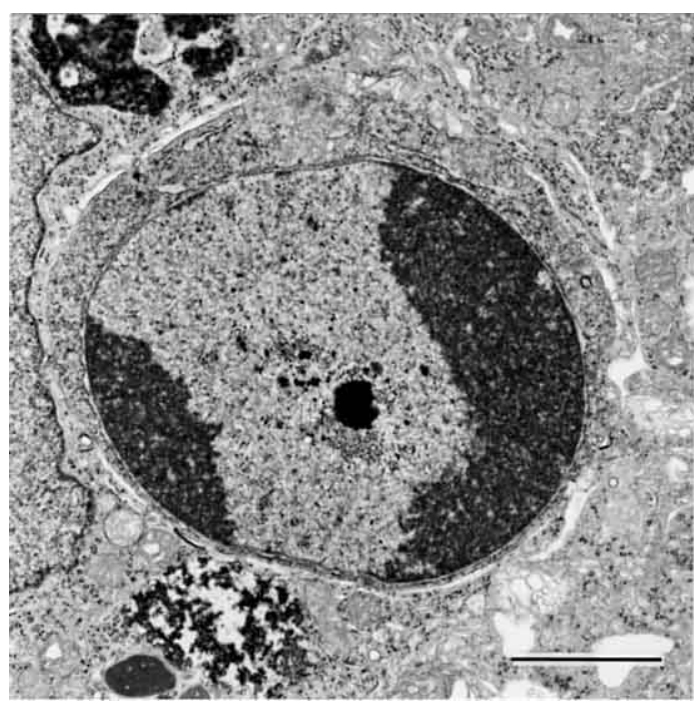

Fig. 3. Electron micrograph of early stage of apoptotic germ cells in the testis at 12 days after birth. $\operatorname{Bar}=2 \mu \mathrm{m}$.

TUNEL-positive germ cells $/ 500$ germ cells was $2.23 \pm 0.17$ in 6-day-old, $10.16 \pm 0.30$ in 12-day-old and $4.13 \pm 0.15$ in 18-day-old mice. The frequency of germ cell apoptosis was the highest in 12-day-old mouse testes when the first wave of spermatogenesis began with active proliferation of spermatogonia.

\section{Electron microscopic analysis of germ cell death during the first wave of spermatogenesis}

The number of degenerating germ cells with unique apoptotic features increased at 12 days after birth and the main population of germ cells comprised spermatogonia. As shown in Figure 3, various stages of germ cell apoptosis were detected at 12 days, as characterized by the intense condensation of chromatin, shrinkage of cellular components, and fragmentation of nuclear material [6]. Consistent with the TUNEL results, typical apoptotic germ cells were also found predominantly in the center part of the seminiferous tubules.

\section{Immunohistochemical localization of Bax and Bcl-2 in neonatal mouse testis}

To clarify the localization pattern of Bax and Bcl-2 in neonatal mouse testes, we performed immunohistochemistry (Figs. 4, 5). Interestingly, Bax staining was detected diffusely in the cytoplasm of gonocytes at the time of birth, but by 6 days after birth, staining was observed in whole cell (Fig. 4a, b). At 12 days after birth (Fig. 4c), two patterns of Bax distribution were present; one was the same as the previous pattern and the other was of whole cell positivity for Bax. Cells with the latter pattern were located in the center part of seminiferous tubules at 12 days and afterwards they were occasionally found in a similar pattern to that of TUNEL-positive cells. In addition, Bax staining was not found in Sertoli cells but was found in the cytoplasm of interstitial cells from the time of birth to 6 days after birth. 

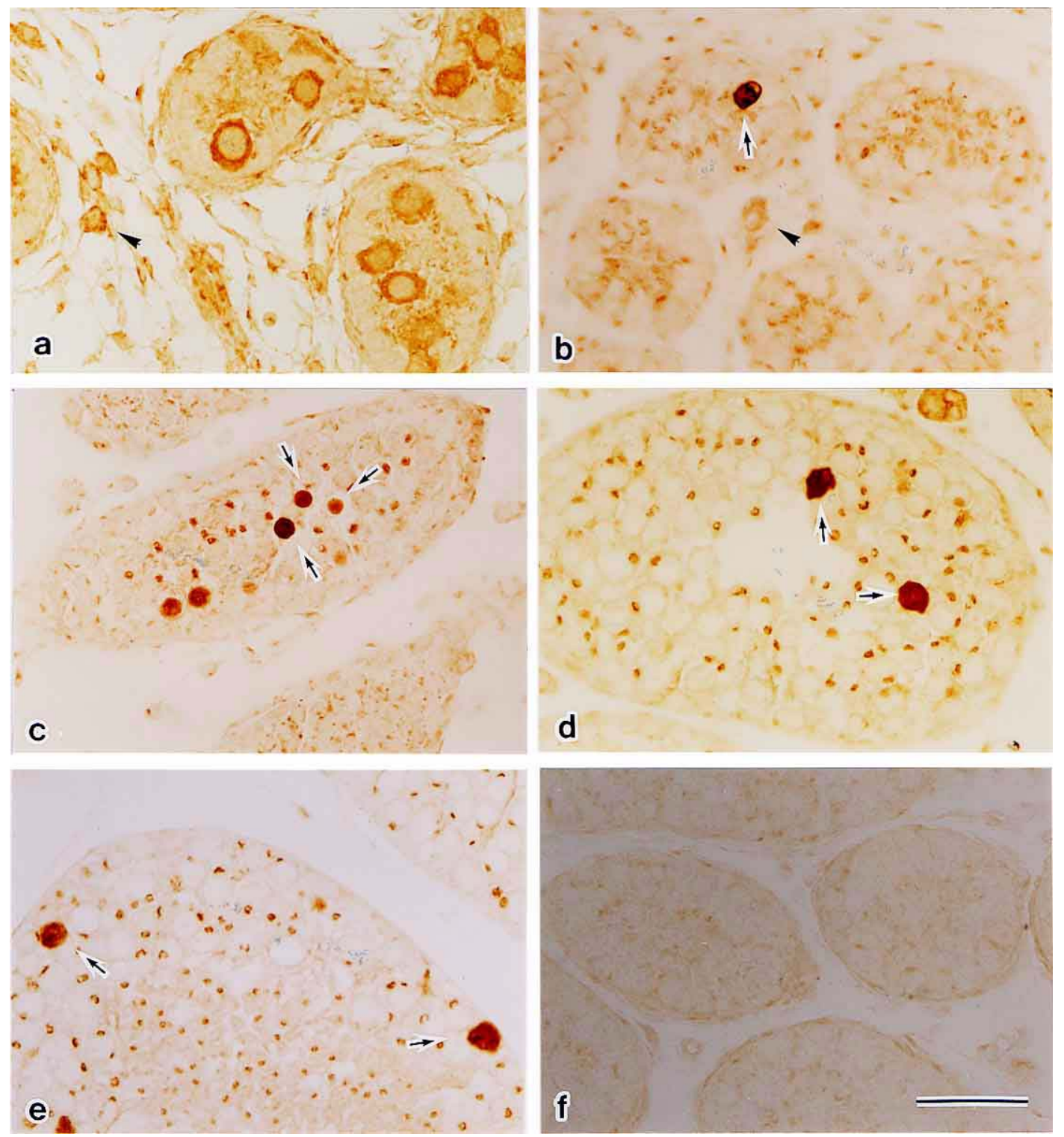

Fig. 4. Immunohistochemical detection of Bax in developing mouse testes. Paraffin embedded sections from postnatal mouse testes at (a) 0 , (b) 6, (c) 12, (d) 18 days and (e) 7 weeks after birth were reacted with anti-Bax antibody. Arrows indicate positive spermatogenic cells and arrowheads positive interstitial cells. (f) Negative control section at 12 days after birth reacted with normal rabbit IgG instead of the specific antibody. Bar $=50 \mu \mathrm{m}$.

In contrast, Bcl-2 staining was detected in spermatocytes after 18 days of age, whereas essentially no signal was present before 18 days after birth (Fig. 5).

\section{Expression of cytochrome $c$ and caspase-3 in neonatal mouse testis}

To gain further insight into the molecular mechanism of induction of germ cell apoptosis in the first wave of spermatogenesis, we examined cytochrome $\mathrm{c}$ and activated caspase-3 expression in neonatal mouse testes using the same sets of paraffin sections that were used for Bax and Bcl-2 immunostaining. As shown in Figure 6, we observed strong staining for cytochrome $\mathrm{c}$ in the cytoplasm of germ cells and the distribution of cytochrome c-positive cells was very similar to that of TUNEL- or Bax-positive cells (Figs. $1,4,6)$. In the case of activated caspase- 3 , the signal was localized to the cytoplasm of germ cells and positive cells were distributed in a similar pattern to that of TUNELpositive cells, Bax-positive cells and cytochrome c-positive cells (Fig. 7).

\section{Close association of TUNEL-positive cells with expression of apoptosis-related proteins in mirror sections of neonatal mouse testis}

The above results suggested a close association of TUNEL-positive germ cells with the expression of Bax, cytochrome $\mathrm{c}$ and activated caspase- 3 . To confirm the association directly, we performed simultaneous localization of 

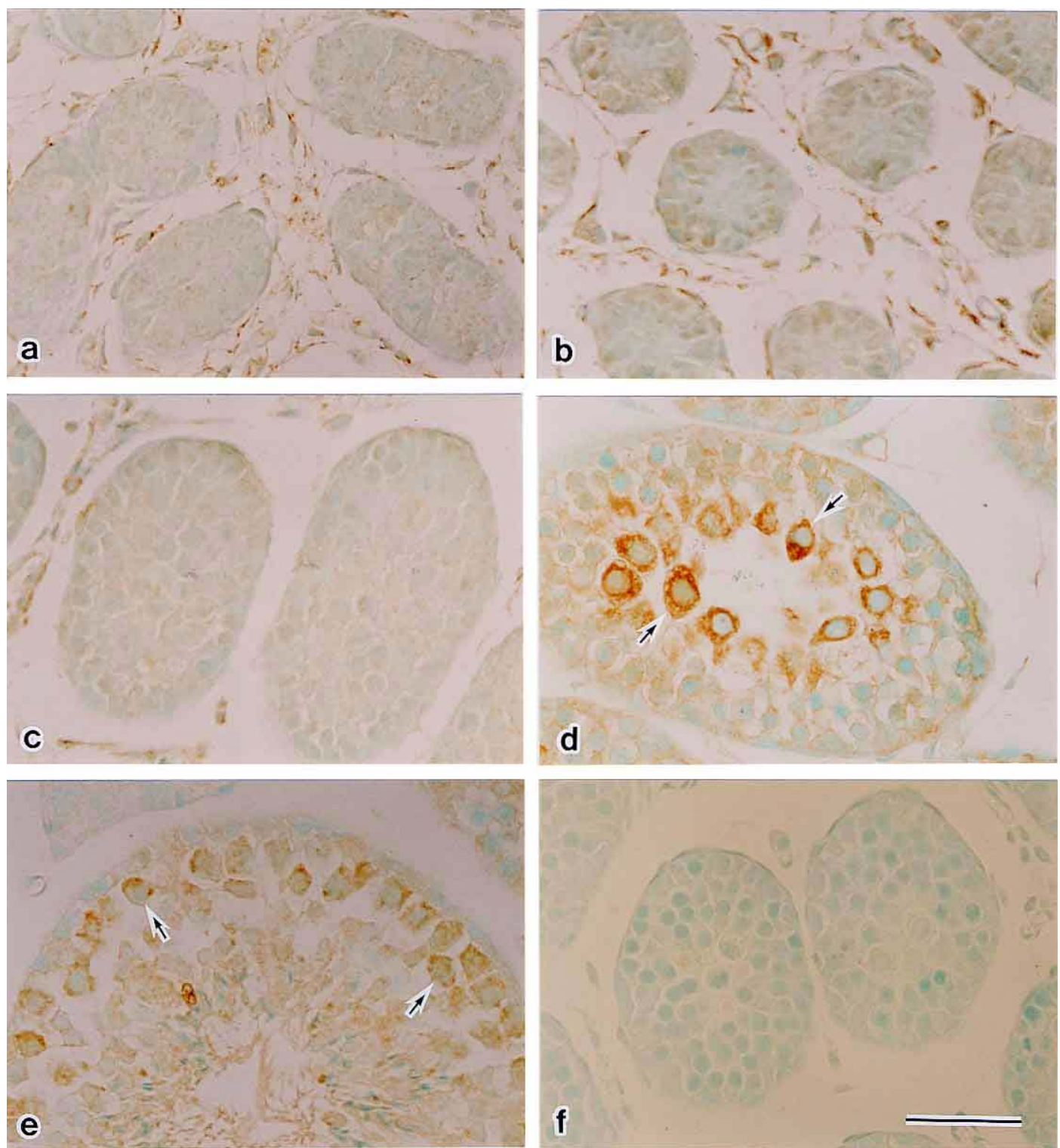

Fig. 5. Immunohistochemical detection of $\mathrm{Bcl}-2$ in developing mouse testes. Paraffin embedded sections from postnatal mouse testes at (a) 0 , (b) 6, (c) 12, (d) 18 days and (e) 7 weeks after birth were reacted with anti-Bcl-2 antibody. Arrows indicate expression of Bcl-2. (f) Negative control at 12 days after birth reacted with normal rabbit IgG instead of specific antibody. Bar=50 $\mu \mathrm{m}$.

these proteins in TUNEL-positive cells in the mirror sections of 12-day-old and adult mouse testes. As shown in Figure 8, we found that TUNEL-positive cells were also positive for Bax, cytochrome c and activated caspase-3, strongly demonstrating the close connection of induction of germ cell apoptosis with the mitochondria-dependent signaling cascade.

\section{Discussion}

In this study, we confirmed the frequent occurrence of spermatogonial apoptosis in the first wave of spermatogenesis in neonatal mouse testis. Furthermore, we showed that germ cell apoptosis is closely associated to redistribution of Bax and expression of cytochrome $\mathrm{c}$ and activated caspase-
3 , which are downstream components in the apoptosisinducing signaling cascade of the Bcl-2/Bax pathway. A similar observation was also made in spontaneous germ cell apoptosis in adult mouse testis. Given that spermatogonial cell death in the neonatal testis was severely retarded in Bax-deficient mice, resulting in over-production of spermatogonia and successive frequent loss of maturing spermatogenic cells in the adult testis [15], these immunohistochemical findings support the notion that neonatal spermatogonial apoptosis may be induced through the mitochondria-dependent cascade, including Bax redistribution.

The biological reason for the triggering of germ cell apoptosis is not clear at present. In some cases, lack of growth factors and/or nutrients provided by Sertoli cells, which therefore have limited capacity for nursing germ cells, and 

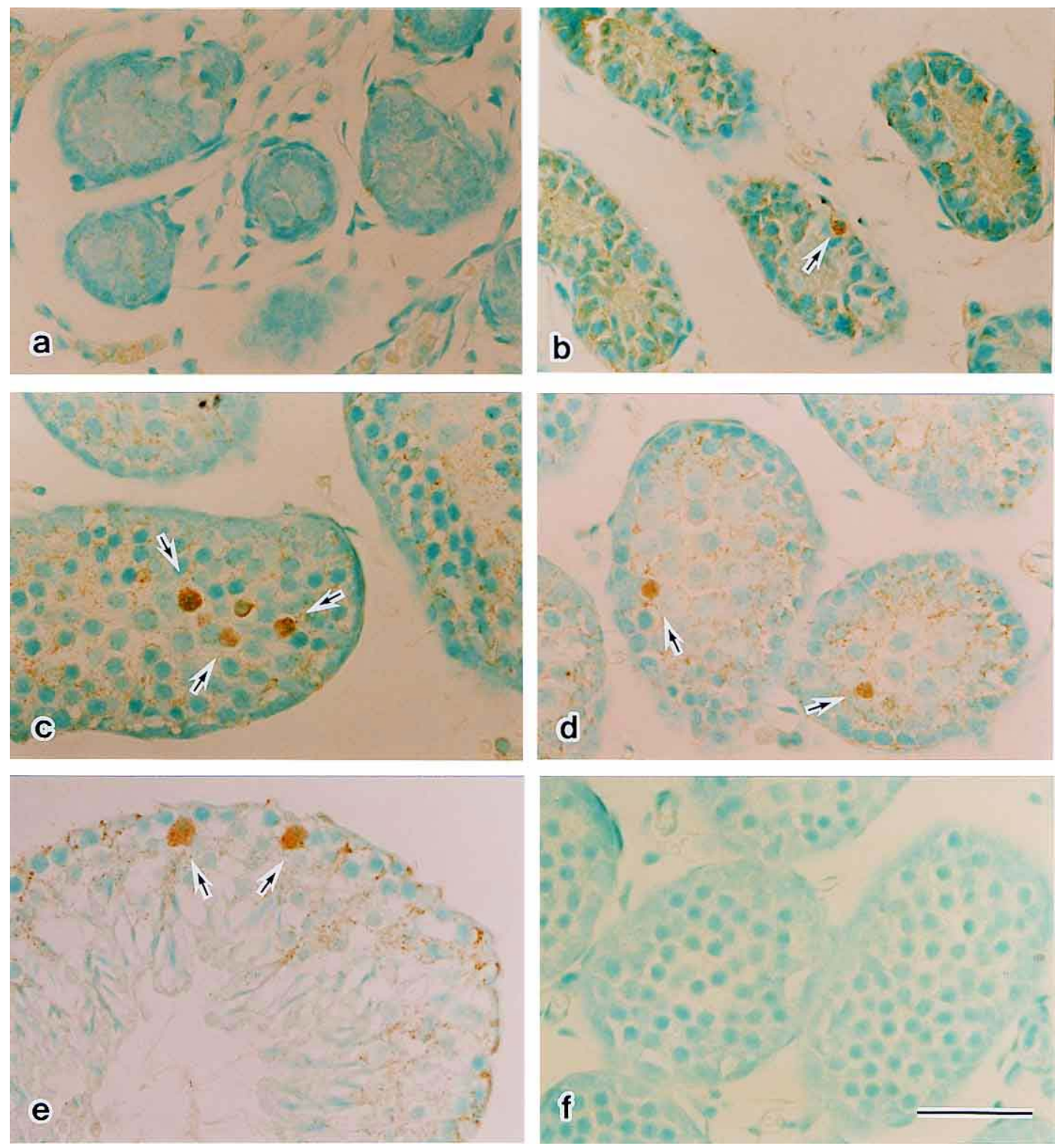

Fig. 6. Immunohistochemical detection of cytochrome $\mathrm{c}$ in developing mouse testes. Paraffin embedded sections from postnatal mouse testes at (a) 0, (b) 6, (c) 12, (d) 18 days and (e) 7 weeks after birth were reacted with anti-cytochrome c antibody. Arrows indicate positive cells. (f) Negative control section at 12 days after birth reacted with normal rabbit IgG instead of the specific antibody. Bar=50 $\mu \mathrm{m}$.

insufficient availability of basement membrane of the seminiferous tubule wall for spermatogonia are thought to induce germ cell apoptosis [14]. Nevertheless, the molecular mechanisms underlying the induction of germ cell apoptosis have been the focus of much research. The Bcl-2 family, which contains both pro-apoptotic (for example, Bax) and antiapoptotic (for example, Bcl-2) members, is interesting as it constitutes an intracellular critical checkpoint that determines cell susceptibility to apoptosis $[1,18]$. However, direct evidence of the association of Bax with induction of germ cell apoptosis in the normal testis has not been forthcoming.

In the present study, immunohistochemistry revealed that the remarkable redistribution of Bax throughout the whole cell might represent an important step in the induction pathway of neonatal germ cell apoptosis. Indeed, Bax translocation from the cytosol to be in close proximity of the nucleus or in the nucleus has been observed in various cell lines upon induction of apoptosis [23, 42]. Movement of Bax from the cytosol to either crude membrane or nuclear compartments has been observed in thymocytes induced to undergo apoptosis by dexamethasone treatment [11]. Therefore, increased expression of the pro-apoptotic molecule Bax accompanying the redistribution, suggests that the induction of germ cell apoptosis in the first wave of spermatogenesis may be due to the triggering of an apoptotic pathway initiated within the mitochondria. If Bax redistribution is involved in the induction of spermatogonial apoptosis in the first wave of spermatogenesis, it may be supposed that release of cytochrome $\mathrm{c}$ from mitochondria occurs at the 

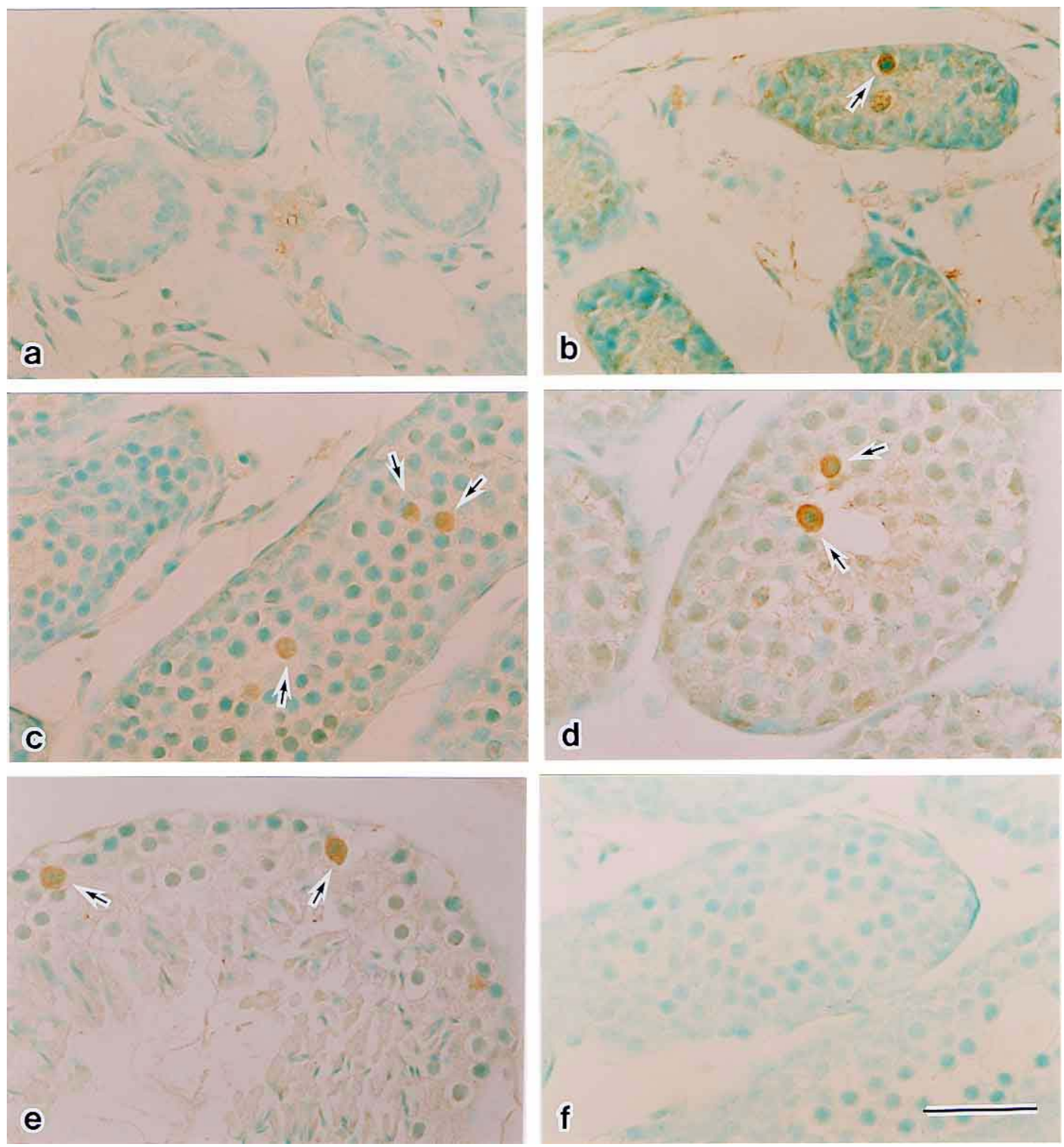

Fig. 7. Immunohistochemical detection of caspase- 3 in developing mouse testes. Paraffin embedded sections from postnatal mouse testes at (a) 0 , (b) 6, (c) 12, (d) 18 days and (e) 7 weeks after birth were reacted with anti-caspase-3. Arrows indicate positive cells. (f) Negative control at 12 days after birth reacted with normal rabbit $\mathrm{IgG}$ instead of specific antibody. Bar=50 $\mu \mathrm{m}$.

same time, followed by activation of caspase-3 [7, 34]. Indeed, in the present study, we found that the whole cell staining for cytochrome c appeared in TUNEL-positive cells, but not in TUNEL-negative cells. Also, those cells were simultaneously positive for anti-activated caspase-3. Interestingly, a similar set of changes in apoptosis-related proteins was found in TUNEL-positive spermatogonia and spermatocytes of normal adult mouse testis. These results, taken together with the previous findings [10], strongly support the notion that apoptosis of normal spermatogenic cells in neonatal and adult mouse testes may be triggered through redistribution of Bax, depending upon the mitochondrial components.

Previously, we and other groups have shown that the Fas and Fas ligand system plays a major role in induction of germ cell apoptosis in various models of adult testicular damage, including ischemia-reperfusion stress $[17,22,36$, 44], treatment with cytotoxic compounds [20], estrogen [5, $21,35]$, and androgen withdrawal [26, 41]. However, during normal spermatogenesis, involvement of the Fas system as an apoptosis-inducing mechanism remained unclear. In addition, Ogi et al. [28] reported that even in Fas-deficient lpr/ $l p r$ mice, germ cell apoptosis was induced by experimental cryptorchidism. Moreover, Richburg et al. [33] showed that exposure of Fas ligand-lacking gld/gld mice to a Sertoli cellspecific toxicant caused only a minimal increase in germ cell apoptosis, whereas these mice were as sensitive as wild-type mice to radiation exposure. Therefore, in the latter Fas-independent cases the mitochondrial pathway can apparently act as a possible inducer of germ cell apoptosis just as in the 

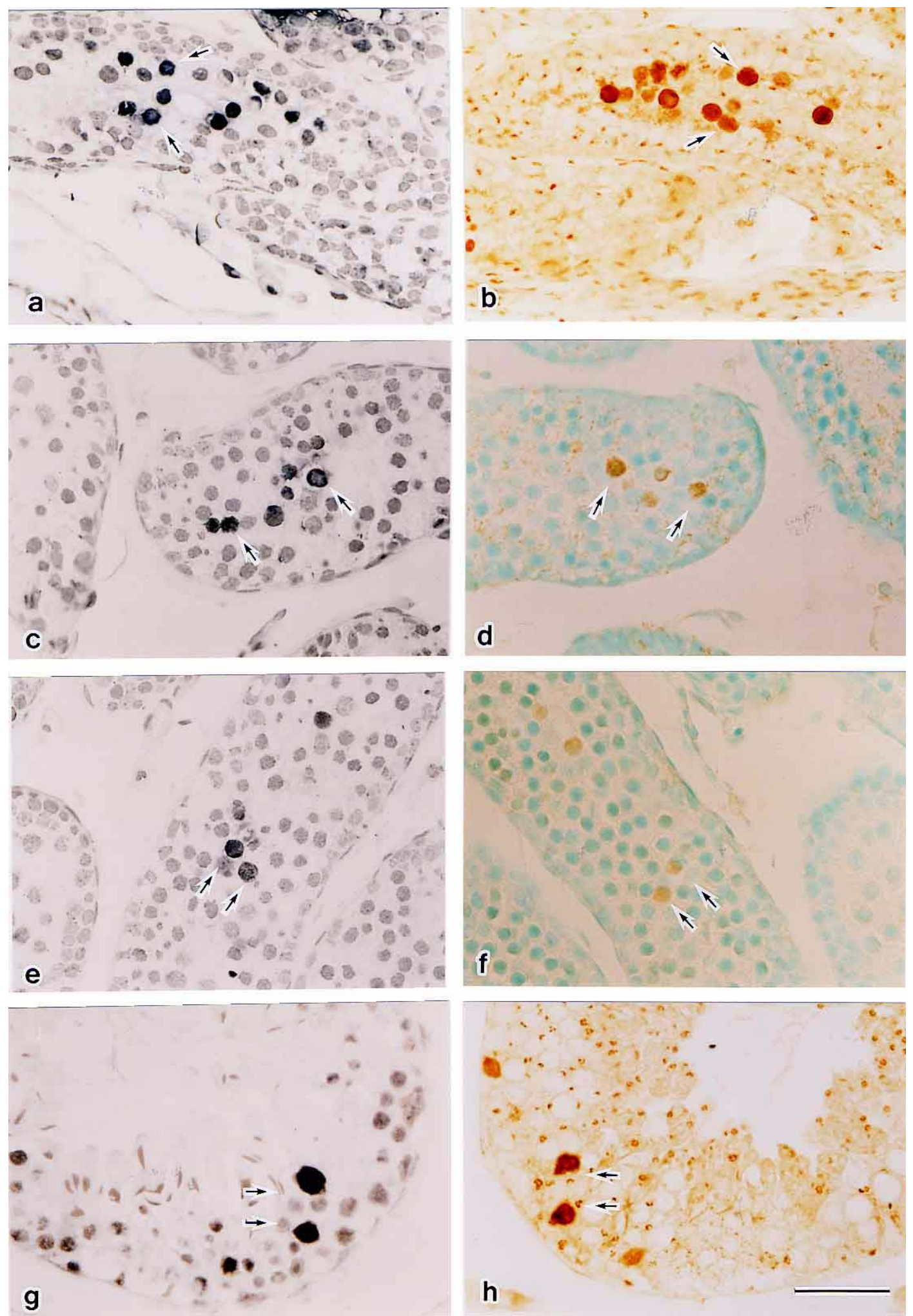

Fig. 8. TUNEL staining (a, c, e) and immunohistochemical detection of Bax, cytochrome $\mathrm{c}$ and caspase-3, respectively (b, d, f) in mirror sections of 12-day-old mouse testes. TUNEL staining (g) and immunohistochemical detection of Bax (h) in mirror sections of adult mouse testis. Arrows indicate positive cells for TUNEL or immmunohistochemistry. Bar $=50 \mu \mathrm{m}$.

case of autonomous germ cell apoptosis in normal spermatogenesis.
Finally, although we identified an essential role for the Bax-related cascade in induction of germ cell apoptosis in 
normal neonatal and adult mice testes, the mechanism that triggers Bax redistribution in a limited number of spermatogonia during the first wave of spermatogenesis remains unknown. Clearly, a more detailed study of the behavior of Bax and related proteins is required.

\section{Acknowledgments}

This study was supported in part by a Grant-in-Aid for Scientific Research from the Japanese Ministry of Education, Sports and Culture (no. 12470003 to T. K.) and a grant from Japanese Environment Agency (to T. K.).

\section{References}

1. Adams, J. M. and Cory, S. (1998) The Bcl-2 protein family: arbiters of cell survival. Science 281; 1322-1326.

2. Baba, N., Koji, T., Itoh, M. and Mizuno, A. (1999) Reciprocal changes in the expression of $\mathrm{Bcl}-2$ and $\mathrm{Bax}$ in hypoglossal nucleus after axotomy in adult rats: possible involvement in the induction of neuronal cell death. Brain Res. 827; 122-129.

3. Bankfalvi, A., Navabi, H., Bier, B., Bocker, W., Jasani, B. and Schmid, K. W. (1994) Wet autoclave pretreatment for antigen retrieval in diagnostic immunohistochemistry. J. Pathol. 174; 223-228

4. Boone, D. L. and Tsang, B. K. (1998) Caspase-3 in the rat ovary: localization and possible role in follicular atresia and luteal regression. Biol. Reprod. 58; 1533-1539.

5. Davies, A. G., Corout, M. and Gresham, P. (1974) Effects of testosterone and follicle-stimulating hormone on spermatogenesis in adult mice during treatment with oestradiol. J. Enocrinol. 60 $37-45$.

6. Gavrieli, Y., Sherman, Y. and Ben-sasson, S. A. (1992) Identification of programmed cell death in situ via specific labeling of nuclear DNA fragmentation. J. Cell Biol. 119; 493-501.

7. Gross, A., Yin, X. M., Wang, K., Wei, M. C., Jockel, J., Milliman, C., Erdjument-Bromage, H., Tempst, P. and Korsmeyer, S. J. (1999) Caspase cleaved BID targets mitochondria and is required for cytochrome $\mathrm{c}$ release, while BCL-XL prevents this release but not tumor necrosis factor R1/Fas death. J. Biol. Chem. $274 ; 1156-1163$

8. Hakuno, N., Koji, T., Kobayashi, N., Tsutsumi, O., Taketani, Y. and Nakane, P. K. (1996) Fas/Apo-1/CD95 system as a mediator of granulosa cell apoptosis in ovarian follicle atresia. Endocrinology $137 ; 1938-1948$.

9. Hashimoto, S., Koji, T., Niu, J., Kanematsu, T. and Nakane, P. K. (1995) Differential staining of DNA strand breaks in dying cells by non-radioactive in situ nick translation. Arch. Histol. Cytol. $58 ; 161-170$

10. Honarpour, N., Du, C., Richardson, J. A., Hammer, R. E., Wang, X. and Herz, J. (2000) Adult Apaf-1-deficient mice exhibit male infertility. Dev. Biol. 218; 248-258.

11. Hsu, Y. T., Wolter, K. G. and Youle, R. J. (1997) Cytosol to membrane redistribution of Bax and Bcl-xl during apoptosis. Proc. Natl. Acad. Sci. U S A 94; 3668-3672.

12. Huckins, C. (1978) The morphology and kinetics of spermatogonial degeneration in normal adult rats: an analysis using a simplified classification of the germinal epithelium. Anat. Rec. 190; 905-926.

13. Johnson, L., Petty, C. S. and Neaves, W. B. (1983) Further quantification of human spermatogenesis: germ cell loss during post prophase of meiosis and its relationship to daily sperm production. Biol. Reprod. 29; 207-215.

14. Kerr, J. F. R., Wyllie, A. H. and Currie, A. R. (1972) Apoptosis: a basic biological phenomenon with wide-ranging implications in tissue kinetics. Br. J. Cancer 26; 239-257.

15. Knudson, C. M., Tung, K. S. K., Toutellotte, W. G., Brown, G. A. J. and Korsmeyer, S. J. (1995) Bax-deficient mice with lymphoid hyperplasia and male germ cell death. Science 270; 96-99.

16. Koji, T. (2001) Male germ cell death in mouse testes: possible involvment of Fas and Fas ligand. Med. Electron. Microsc. 34; 213-222.

17. Koji, T., Hishikawa, Y., Ando, H., Nakanishi, Y. and Kobayashi, N. (2001) Expression of Fas and Fas ligand in normal and ischemia-reperfusion testes: involvement of the Fas system in the induction of germ cell apoptosis in the damaged mouse testis. Biol. Reprod. 64; 946-954.

18. Korsmeyer, S. J. (1999) Bcl-2 gene family and the regulation of programmed cell death. Cancer Res. 59; 1693s-1700s.

19. Krajewski, S., Krajewska, M., Shabaik, A., Miyashita, T., Wang, H. G. and Reed, J. C. (1994) Immunohistochemical determination of in vivo distribution of Bax, a dominant inhibitor of Bcl-2. Am. J. Pathol. 145; 1323-1336.

20. Lee, J., Richburg, J. H., Younkin, S. C. and Boekelheide, K. (1997) The Fas system is a key regulator of germ cell apoptosis in the testis. Endocrinology 138; 2081-2088.

21. Libbus, B. L. and Schuetz, A. W. (1980) Gonadotrophin-induced reinitiation of meiosis in testes of oestradiol-treated prepubertal rats. J. Reprod. Fertil. 60; 1-6.

22. Lysiak, J. J., Turner, S. D. and Turner, T. T. (2000) Molecular pathway of germ cell apoptosis following ischemia/reperfusion of the rat testis. Biol. Reprod. 63; 1465-1472.

23. Mandal, M., Adam, L., Mendelsohn, J. and Kumar, R. (1998) Nuclear targeting of bax during apoptosis in human colorectal cancer cells. Oncogene 17; 999-1007.

24. Mc Carrey, J. R. (1993) Development of the germ cell. In "Cell and Molecular Biology of the Testis", ed. by C. Desjardins and L. L. Ewing, Oxford Univrsity Press Inc., New York, pp. 58-89.

25. Meehan, T., Loveland, K. L., de Kretser, D., Cory, S. and Print, C. G. (2001) Developmental regulation of the bcl-2 family during spermatogenesis: Insights into the sterility of bcl-w -/- male mice. Cell Death Differ. 8; 225-233.

26. Nandi, S., Banerjee, P. P. and Zirkin, B. R. (1999) Germ cell apoptosis in the testes of Sprague Dawley rats following testosterone withdrawal by ethane 1,2-dimethane sulfonate administration: relationship to Fas? Biol. Reprod. 61; 70-75.

27. Oakberg, E. F. (1956) A description of spermatogenesis in the mouse and its use in analysis of the cycle of seminiferous epithelium and germ cell renewal. Am. J. Anat. 99; 391-413.

28. Ogi, S., Tanji, N., Yokoyama, M., Takeuchi, M. and Terada, N. (1998) Involvement of Fas in the apoptosis of mouse germ cells induced by experimental cryptorchidism. Urol. Res. 26;17-21.

29. Oltvai, Z. N., Milliman, C. L. and Korsmeyer, S. J. (1993) Bcl-2 heterodimerizes in vivo with a conserved homolog, Bax, that accelerates programmed cell death. Cell 74; 609-619.

30. Otsuki, Y. (2000) Various method of apoptosis detection. Acta Histochem. Cytochem. 33; 235-241.

31. Packer, A. I., Besmer, P. and Bachvarova, R. F. (1995) Kit ligand mediates survival of type A spermatogonia and dividing spermatocytes in postnatal mouse testes. Mol. Reprod. Dev. 42; 304310.

32. Print, C. G. and Loveland, K. L. (2000) Germ cell suicide: new insights into apoptosis during spermatogenesis. Bioessays 22; 423-430.

33. Richburg, J. H., Nanez, A., Williams, L. R., Embree, M. E. and Boekelheide, K. (2000) Sensitivity of testicular germ cells to toxicant-induced apoptosis in gld mice that express a nonfuncional form of Fas ligand. Endocrinology 141; 787-793.

34. Salvesen, G. S. and Dixit, V. M. (1999) Caspase activation: the induced proximity model. Proc. Natl. Acad. Sci. U S A 96; 10964-10967. 
35. Schulze, C. (1988) Response of the human testis to long-term estrogen treatment: morphology of Sertoli cells, Leydig cells and spermatogonial stem cells. Cell Tissue Res. 251; 31-43.

36. Shiraishi, K., Naito, K. and Yoshida, K. (2001) Nitric oxide promotes germ cell necrosis in the delayed phase after experimental testicular torsion of rat. Biol. Reprod. 65; 514-521.

37. Sun, F., Akazawa, S., Sugahara, K., Kamihira, S., Kawasaki, E., Eguchi, K. and Koji, T. (2002) Apoptosis in normal rat embryo tissues during early organogenesis: the possible involvement of Bax and Bcl-2. Arch. Histol. Cytol. 65; 145-157.

38. Tamura, M., Kimura, H., Koji, T., Tominaga, T., Ashizawa, K., Kiriyama, T., Yokoyama, N., Yoshimura, T., Eguchi, K., Nakane, P. K. and Nagataki, S. (1998) Role of apoptosis thyrocytes in a rat model of goiter. A possible involvement of Fas system. Endocrinology 139; 3646-3653.

39. Vaux, D. L. and Korsmeyer, S. J. (1999) Cell death in development. Cell 96; 245-254.

40. Wang, R. A., Nakane, P. K. and Koji, T. (1998) Autonomous cell death of mouse male germ cells during fetal and postnatal period.
Biol. Reprod. 58; 1250-1256.

41. Woolveridge, I., de Boer-Brouwer, M., Taylor, M. F., Teerds, K. J., Wu, F. C. W. and Morris, I. D. (1999) Apoptosis in the rat spermatogenic epithelium following androgen withdrawal: changes in apoptosis-related genes. Biol. Reprod. 60; 461-470.

42. Yamamoto, C. M., Sinha Hikim, A. P., Huynh, P. N., Shapiro, B., Lue, Y., Salameh, W. A., Wang, C. and Swerdloff, R. S. (2000) Redistribution of Bax is an early step in an apoptotic pathway leading to germ cell death in rats, triggered by mild testicular hyperthermia. Biol. Reprod. 63; 1683-1690.

43. Yang, E. and Korsmeyer, S. J. (1996) Molecular thanatopsis: a discourse on the Bcl-2 family and cell death. Blood 88; 386-401.

44. Yin, Y., Dewolf, W. C. and Morgentaler, A. (1998) Experimental cryptorchidism induces testicular germ cell apoptosis by p53dependent and -independent pathways in mice. Biol. Reprod. 58; 492-496.

45. Zhou, Z., Sun, X. and Kang, Y. J. (2001) Ethanol-induced apoptosis in mouse liver Fas- and cytochrome c-mediated caspase-3 activation pathway. Am J. Pathol. 159; 329-338. 